\title{
AOR
}

Selected Papers of \#AoIR2021:

The 22nd Annual Conference of the

Association of Internet Researchers

Virtual Event / 13-16 Oct 2021

\section{INTERDEPENDENCE AND NETWORK OVERSIGHT IN 1990S INTERNET GOVERNANCE}

\author{
Meghan Grosse \\ Washington College

\section{Introduction} \\ In October 2016, the contract between the United States Department of Commerce and \\ the Internet Corporation for Assigned Names and Numbers (ICANN) officially expired. \\ This contract represented a long-standing and close relationship between the United \\ States government and ICANN, a relationship that positioned the U.S. as a kind of \\ linchpin in determining the shape and coordination of the global, extraterritorial internet. \\ In particular, the policies and standards set by ICANN established a shared root server \\ system that enabled the operation of a globally interconnected network. This research \\ seeks to address the question: what interests and values shaped ICANN at the time of \\ its establishment and in what ways do debates about this system reflect broader \\ concerns about the U.S.-centric nature of early internet governance policy?
}

The contract between these organizations, ICANN and the U.S. Government, dates back to the mid-1990s, and so this research focuses on the debates and policy decisions happening during that time period. The governance policies set during this time have continued to impact the internet to this day, and so I return to this constitutive moment in the history of the internet, a moment when "choices about how things are built and how they work - their design and rules of operations" were made, in order to explore the values and interests that were protected and promoted through internet governance policy (Starr, 2004, p. 4).

The 2016 change in ICANN oversight and the discussions that led to that decision highlight the ongoing concerns about the U.S.'s central position in setting internet governance policy and in overseeing the network's management. If we look back at the discussions happening in the 1990s, it becomes clear that many of these concerns had gone unanswered or unresolved at that time. I return to this history in order to better contextualize contemporary debates around internet governance and to understand the ongoing need to address the inequalities built into that system.

Suggested Citation (APA): Grosse, M., (2021, October). Interdependence and Network Oversight in 1990s Internet Governance. Paper presented at AoIR 2021: The 22nd Annual Conference of the Association of Internet Researchers. Virtual Event: AolR. Retrieved from http://spir.aoir.org. 


\section{Methods/Critical Frameworks}

I examine early internet governance and the discourses of independence and interdependence that emerged during that time through archival analysis. This research focuses on documents found in the Ira Magaziner Electronic Commerce papers at the Clinton Presidential Library in Little Rock, Arkansas. This archive primarily represents the work on internet governance undertaken within the Department of Commerce, the department under which Clinton moved internet governance policy - a shift away from previous oversight coming from the Department of Defense and the National Science Foundation. I apply a political economy of communication framework to this analysis, focusing on concerns for power - who wielded power in establishing the network structures that continue to influence the internet we use today and who pushed back and advocated for a different kind of internet.

In reviewing materials from this archive, three primary groups are represented in the materials: 1) official government actors from the U.S. and around the world and representatives from various intergovernmental organizations working on issues like trade, intellectual property, and taxation; 2) technical experts who were early adopters of internet technology and who generally understood the mechanics of the internet as well as its capacities and limitations; and 3) commercial interests - broadly the companies and for-profit organizations that were investing and operating on the early internet. In examining the discussions happening between and among these different groups, I argue that the U.S. government positioned itself at the center of policymaking on governance issues, doing so with little effort to meaningful integrate critiques coming from other countries and with almost no effort to consider a future for the internet other than the commercial one they envisioned.

\section{Findings/Conclusions}

In 1994, the administration of U.S. president Bill Clinton stated publicly that the commercialization of the internet was a top priority for the U.S. government, and they remained consistently committed to this vision (Goldsmith \& Wu, 2008, p. 40). In their policy, "A Framework for Global Electronic Commerce," the U.S. Government, led by the efforts of Ira Magaziner, offered 5 principles that should guide governance of the global internet. First and foremost they stated: "The private sector should lead." Every principle that followed largely served to clarify and reinforce this first principle. Where government was to be involved, "its aim should be to support and enforce a predictable, minimalist, and consistent legal environment for commerce" and otherwise "should avoid undue restrictions on electronic commerce" (A Framework for International Electronic Commerce, 1996). With these principles in mind, the Clinton Administration focused on establishing, controlling, and protecting a domain name system (DNS) that would encourage private sector investment and offer a stable network to encourage trust in the network, by both businesses and consumers. In the interest of protecting commercial interests while also promoting private sector oversight, the U.S. government supported the creation of ICANN.

Pushing away from traditional governance by states, ICANN was set up to coordinate a global system while acting as "one of the few globally centralized points of control over 
the internet" (Mueller, 2010, p. 61). Rather than maintain state control and policymaking authority, the Clinton Administration placed this privilege in the hands a private corporation. Despite this move towards privatization, the U.S. government still had some oversight here. Controversially, ICANN was accountable to only one nation even as it was described as a global system, seen by some as "expression of unilateral globalism" (p. 62).

\section{Connection to Conference Themes}

This paper addresses concerns related to independence, and in particular, focuses on the systems of interdependence established in early internet governance policy. In the mid-1990s, the U.S. positioned itself as a leader in global internet governance, overseeing ICANN and by extension the root server system upon which all internet users would rely. While espousing the values of competitive free-market, the U.S. proposal raised concerns about the concentration of power and potentially monopolistic control of the network by a single nation. These concerns were not outliers, but were coming from some of the U.S.'s closest partners in discussing internet governance policies - the E.U. and Spain. In order to establish an internet that would work to support global electronic commerce, the U.S. promoted a system of governance that left little room for true multistakeholderism, the very principle that was central to the 2016 change in ICANN oversight. These concerns were not new, but rather represent a longstanding debate in the history of internet governance. Understanding the foundations of those debates helps better understand not just this change, but ongoing discussions about how to best create a truly representative global internet.

\section{References}

A Framework for International Electronic Commerce. (1996). Box 003, Folder 100011 10379 100011-010. Ira Magaziner Electronic Commerce Papers, William J. Clinton Presidential Library Archives, Little Rock, Arkansas, United States.

Goldsmith, J. and Wu, T. (2008). Who controls the internet? Oxford: Oxford University Press.

Mueller, M. (2010). Networks and states: The global politics of internet governance. Cambridge, MA: The MIT Press.

Starr, P. (2004). The creation of the media: Political origins of modern communication. New York, NY: Basic Books. 